\section{Diffusion Chambers for the Collection of Helminth Antigens}

Is comparing the immunological responsiveness, in relation to a particular nematode, of old-established hosts on one hand and newly established hosts on the other ${ }^{1}$, it was necessary to obtain an antigen which could be presumed to have been immunologically active over evolutionary time, that is, a natural product of normal infection. It was therefore essential to collect the excretions and secretions of worms living under conditions resembling as nearly as possible the natural environment, in this instance the liver and abdominal cavity of rats.

Recourse was made to diffusion chambers for this purpose, the principle involved being to transfer thirdstage larvæ from the original host to the diffusion chamber, which was then inserted into the abdominal cavity of a recipient host. Larvæ removed from the donor 5 weeks6 months after experimental infection were observed to remain alive in the capsules for at least a week.

The technique involved removal of 10-15 worms from the abdominal cavity under aseptic conditions and their insertion into the capsule, which was then inserted into the peritoneal cavity, which had been opened by midline incision. The recipient rats were given intramuscular benethamine penicillin ( 10,000 I.U.) and $0.03 \mathrm{~g}$ streptomycin sulphate after the insertion of the capsule, which was left in situ for 7-10 days, then removed and opened. The contents of the capsule were washed out with about 1 c.c. of sterile distilled water and, after separation of the worms, the fluid was centrifuged and used as antigen.

The diffusion chambers were made from three types of membrane, each with a different pore size. The first type $(D C 1)$ was made from size $8 / 32$ Visking dialysis tubing (Visking Co., Chicago). About $18 \mathrm{~cm}$ of the tubing was cut and sterilized by placing in 1 per cent 'CetavlonHibitane' solution (Imperial Chemical Industries, Ltd.) for $48 \mathrm{~h}$ before use. One end was tied off and the worms were inserted into the open end with about 3 c.c. of sterile physiological saline. The other end was then tied off and both ends carefully trimmed, so as to leave as little rough edge as possible.

The other capsules (DC2 and $D C 3$ ) were made from membranes prepared by 'Membranfilter', Göttingen, Germany. Two 50-mm membranes were used to form each capsule. The two sizes used were 'Membranfilter Gruppe 5' $(D C 2)$ and 'Ultrafein Filter' (DC3). These capsules were prepared by means of a carpenter's ' $G$ ' clamp and two stainless cylindrical moulds $29 \mathrm{~mm}$ diam. and $19 \mathrm{~mm}$ thick (Fig. 1). On one of the flat sides of each

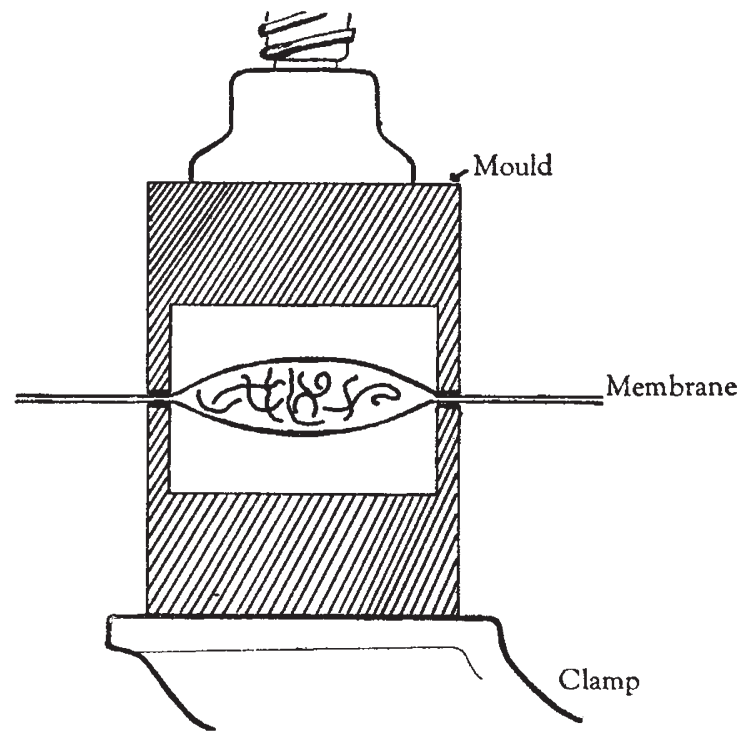

Fig. 1. Diagram showing preparation of capsules DC2 and DC3 mould was a depression $25 \mathrm{~mm}$ diam. and $9 \mathrm{~mm}$ depth. One 50-mm circular sheet of membrane was placed over the mould with the depression uppermost. The worms in sterile physiological saline were pluced on the membrane, which was pushed into the depression on the mould. Another membrane was placed over the worms and the second mould, with depression downwards, was placed over this membrane. The two moulds were placed in the clamp and tightly opposed. The opposing membrane edges, protruding outside the moulds, were then joined with acetone, trimmed, and after a fow seconds for drying, they were removed from between the moulds by loosening the clamp. After washing in sterile distilled water, the chamber was now ready for insertion.

The fluid obtained from the different chambers $(D C 1$, $D C 2$ and $D C 3$ ) was tested by the complement fixation reaction and by gel-diffusion against sera from infected rabbits and rats, as well as against normal serum, and against the serum of rats after harbouring the capsules. The fluid from each disk geve positive complement fixation, and strong Ouchterlony gel diffusion lines with infected rabbit sera. With infected rat sera no complement fixation occurred, the serum showing anticomplementary activities, but gel-diffusion lines were strongly developed. No reaction occurred with normal rabbit and rat sera, or with the sera of rats harbouring the capsules.

The contents of the three types of capsule varied in reactivity with infected rabbit serum, that obtained from capsule $D C l$ showing a higher complement fixation titre than that from capsules $D C 2$ and $D C 3$.
J. F. A. SPRENT
R. S. Hogarth ScotT

H. TIMOURIAN

Department of Parasitology,

University of Queensland,

St. Lucia, Brisbane. ${ }^{2}$ Sprent, J. F. A., in The Evolution of Living Organisms, edit. by Leeper, Singapore, Nov. 5-9, 1962; Parasitol., 53, 7, 321 (1963).

\section{ENTOMOLOGY}

\section{Histology and Possible Functions of Neuro- secretory Cells in the Ventral Ganglia of Schistocerca gregaria Forsk.}

ALthough neurosecretory cells were shown to exist in the ventral ganglia of insects as early as $1940^{1}$, students of neurosecretion in the group have concentrated on the brain and rather neglected the ventral nerve-cord. This neglect prompted me in 1959 to begin studying the ventral ganglia of Schistocerca gregaria (Orthoptera : Acrididae) in some detail, and though, since starting the work, three papers on the histology of the ventral ganglia of other insects have appeared ${ }^{2-4}$, a summary of the rather different conditions in Schistocerca seems desirable.

All four main types of neurosecretory cells found in insects and often denoted, for example by Highnam ${ }^{5}$, as $A, B, C$ and $D$ cells have been shown to occur in the ventral ganglia of $S$. gregaria (Fig. I). The $B$ cells are not phloxinophil, however, and therefore not identical with the $B$ cells of the pars intercerebralis of the brain ${ }^{5}$. The $B, C$ and $D$ cells occur in all the ventral ganglia, but their number and position vary from one insect to another. The $A$ cells are constant in number and location, and occur in all ventral ganglia except the last abdominal one. Neurosecretory cells are absent from the frontal, hypocerebral and ingluvial ganglia of the stomatogastric nervous system.

The $A$ cells may be divided into three sub-types : $A$, $A 2$ and $A 3$ cells. The $A 1$ cells are peculiar in undergoing great changes in volume during sexual maturation of the female, while the $A 2$ cells are unique in that their secretory material appears in Azan-stained sections as large droplets which are coloured brilliant red with azocarmine. Both 